\title{
Effect of 20-Hydroxyecdysone on Proteolytic Regulation in Skeletal Muscle Atrophy
}

\author{
MUTHITA HIRUNSAI ${ }^{1,2}$, TOSSAPORN YIMLAMAI ${ }^{2,3}$ and APICHART SUKSAMRARN ${ }^{4}$ \\ ${ }^{1}$ Department of Biopharmacy, Faculty of Pharmacy, Srinakharinwirot University, Nakhon Nayok, Thailand; \\ ${ }^{2}$ Department of Physiology, Faculty of Science, Mahidol University, Bangkok, Thailand; \\ ${ }^{3}$ Faculty of Sports Science, Chulalongkorn University, Pathumwan, Bangkok, Thailand; \\ ${ }^{4}$ Department of Chemistry, Faculty of Science, Ramkhamhaeng University, Bangkapi, Bangkok, Thailand
}

\begin{abstract}
Background/Aim: 20-Hydroxyecdystone (20E) is an ecdysteroid hormone which controls molting and reproduction in arthropods. $20 \mathrm{E}$ also produces a variety of effects in vertebrates, including enhancing protein synthesis and skeletal muscle regeneration. The effect of $20 \mathrm{E}$ on disuse muscle atrophy has not been reported to date. This study examined the proteolytic regulation of $20 E$ in tenotomized rat slow soleus and fast plantaris muscles. Materials and Methods: Male Wistar rats were randomly divided into three groups: sedentary control (CON), tenotomy without $20 E$ treatment (TEN), and tenotomy with treatment of $5 \mathrm{mg} / \mathrm{kg} \mathrm{BW}$ of $20 E(T E N+20 E)$. The TEN+2OE group was administered $20 E$ via subcutaneous injection to the right thigh for 7 days after tenotomy. Results: $20 \mathrm{E}$ treatment tended to attenuate disuse muscle atrophy and reduced ubiquitination only in soleus muscle. Conclusion: 20E treatment alleviates skeletal muscle atrophy partially mediated by ubiquitinate pathway, dependent on the muscle phenotype.
\end{abstract}

Skeletal muscle atrophy is a debilitating condition associated with a variety of pathological conditions (e.g. diabetes mellitus, cancer, chronic obstructive pulmonary disease, and chronic heart failure), physiological consequence of aging (sarcopenia), and disuse (e.g. casting-immobilization, microgravity, or tendon injury), subsequently leading to a decrease in mobility and reduced quality of life (1). Muscle atrophy is characterized by a decrease of protein content leading to a reduction in cross-sectional area (CSA) of

Correspondence to: Muthita Hirunsai, Ph.D., Department of Biopharmacy, Faculty of Pharmacy, Srinakharinwirot University, Rangsit-Nakhon Nayok Road, Ongkharak, Nakhon Nayok 26120 Thailand. Tel. +66 37395094, Fax: +66 37395096, e-mail: muthitah@hotmail.com,muthita@swu.ac.th

Key Words: Ecdysteroid, MURF1, muscle-type specific, tenotomy, ubiquitin. muscle fibers and impairment of muscle force generation and fatigue resistance $(2,3)$. Skeletal muscle mass is determined by the balance of protein synthesis and protein breakdown. However, previous compelling evidence has indicated that disuse muscle atrophy is primarily caused by the increase in the rate of protein degradation rather than a decrease in the rate of protein synthesis (4). Although several proteolytic systems are involved in protein turnover in skeletal muscle, recent studies suggested that the ubiquitin-proteasome system (UPS) represents the major intracellular proteolysis machinery responsible for the degradation of major contractile proteins, and contributes significantly to muscle atrophy in both animal and human models $(1,5)$.

To date, in spite of many attempts, there is no single effective method to completely cure muscle atrophy. Although several pharmacological agents such as $\beta 2$ adrenergic agonist or proteasome inhibitors have been prescribed to combat muscle atrophy (5), these drugs do not come without side-effects. Therefore, a search for a nonpharmacological therapeutic strategy should be considered as an alternative approach to tackle these clinical problems. There is evidence that ecdysteroids, insect hormones, have an anabolic effect on skeletal muscle (6) with no side-effects in mammals, including humans (7).

Ecdysteroids act as molting hormones in insects and also play a defensive role against insect herbivory in plants (8). There are a large number of structurally related ecdysteriods in plants (phytoecdysteriods). Of these, 20-hydroxyecdysone (20E) is the most commonly found and extensively studied. This compound is present at high concentration in the bark of blackberry tree (Vitex glabrata). 20E has low toxicity in mammals: the lethal dose $50\left(\mathrm{LD}_{50}\right)$ is $6.4 \mathrm{~g} / \mathrm{kg}$ in mice for intraperitoneal injection and more than $9 \mathrm{~g} / \mathrm{kg}$ when given orally (9). The pharmacokinetics of $20 \mathrm{E}$ depend on the mode of administration, for example, the half-time of elimination of this substance in lambs when administered via oral, intravenous, and intramuscular routes were $0.2,0.4$, and $2 \mathrm{~h}$, respectively (10). It has been reported that the half-life of 
$20 \mathrm{E}$ was shorter in smaller animals e.g., 8 minutes 15 seconds in mice (11). 20E was taken up by the liver, excreted into the gut via bile, and then eliminated into urine and faces in mice (12).

Ecdysteroids have a variety of physiological effects in mammals, including hepatoprotective, immune modulatory, as well as hypoglycemic action. Notably, 20E affects certain major metabolic pathways such as protein synthesis, and lipid and carbohydrate metabolism (13). One of the most interesting properties of ecdysteroids in mammals is their anabolic effect, similar to anabolic steroids, but without the androgenic effect (14). Various preparations (e.g. Ekdisten ${ }^{\circledR}$ or Retibol ${ }^{\circledR}$ ), containing a small amount (about $5 \mathrm{mg} / \mathrm{tablet}$ ) of ecdysteroid have been used among body builders and sportsman as an ergogenic aid to enhance physical performance (12). Anabolic action of $20 \mathrm{E}$ includes increased fiber size in a muscle-specific manner, as well as increasing the myonuclear number in both of normal and regenerating muscles in rat (15). Furthermore, it was reported to enhance physical performance, as measured by a forced swimming test, without training in rats (16). 20E stimulates in dosedependent manner $\left[{ }^{3} \mathrm{H}\right]$ leucine incorporation into muscle proteins of $\mathrm{C} 2 \mathrm{C} 12$ and isolated human skeletal cells mediating protein kinase B (AKT) activation (17). Although $20 \mathrm{E}$ has anabolic action, the response of the muscle proteolytic pathway to this compound is still unknown. Therefore, the primary goal of this study was to evaluate the effect of $20 \mathrm{E}$ on the activation of the UPS in rat skeletal muscle atrophy induced by Achilles tendon transection. The reason behind our selecting this animal model is that this type of atrophy is very commonly encountered by clinicians following orthopedic surgery or degenerative musculoskeletal diseases (18); moreover, tenotomy is reproducible in inducing muscle atrophy. Additionally, there is accumulating evidence that slow-twitch fibers are more sensitive to inactivity or microgravity than fast-twitch fibers $(19,20)$, and $20 \mathrm{E}$ enhances muscle hypertrophy of different fiber types in a muscle-specific fashion (15). Thus, the second goal of this study was to evaluate whether $20 \mathrm{E}$ induces a fiber type-specific response of proteolytic regulation of tenotomy-induced muscle atrophy in slowdominant soleus and fast-dominant plantaris muscles.

\section{Materials and Methods}

20-Hydroxyecdysteroid. 20E was isolated from the bark of Vitex glabrata using the literature-described procedure (21). The physical and spectroscopic (nuclear magnetic resonance and mass spectra) data of the isolated compound were found to be in accordance with the literature values $(22,23)$.

Animals and treatment. Adult male Wistar rats (10 weeks old), weighing approximately 290-310 g, were obtained from the National Laboratory Animal Centre, Salaya, Nakhon Pathom,
Thailand. All animal procedures and experiments were conducted with the approval of the animal use and care guidelines established by the Ethics Committee on the Use of Experimental Animals, Faculty of Science, Mahidol University (protocol no. MUSC54-034244). Rats were randomly assigned to three groups ( $n=8$ in each group): controls (CON) received vehicle [olive oil plus dimethyl sulfoxide (DMSO; not exceeding 10\% of volume injected)]; tenotomy without $20 \mathrm{E}$ treatment (TEN), which received vehicle; and tenotomy with $20 \mathrm{E}$ treatment $(\mathrm{TEN}+20 \mathrm{E})$ received $20 \mathrm{E}$ at a dose of $5 \mathrm{mg} / \mathrm{kg} \mathrm{BW}$ diluted in vehicle. Vehicle or $20 \mathrm{E}$ treatment were applied to the animal via subcutaneous injection into the right thigh for seven consecutive days after tenotomy. All rats were housed at $21^{\circ} \mathrm{C}$ and maintained on a $12: 12 \mathrm{~h}$ light-dark cycle. In order to eliminate confounding factors of food intake between groups, animals were pair-fed with standard food and water. Rats were sacrificed $24 \mathrm{~h}$ after the last vehicle or $20 \mathrm{E}$ treatment.

Tenotomy. Rats were anesthetized with a cocktail of tiletamine and zolazepam (Zoletil ${ }^{\circledR} ; 25 \mathrm{mg} / \mathrm{kg}$, i.p.) and xylazine ( $8 \mathrm{mg} / \mathrm{kg}$, i.p.). All surgical procedures were performed under aseptic technique. The right hindlimb was cleaned with betadine solution to prevent infection, then the skin of the calf down to the Achilles tendon and calcaneous bone was incised. The Achilles tendon was carefully excised from the distal part attached with calcaneous bone to the proximal part for $3 \mathrm{~mm}$ in length without disturbing the nerve and blood supply. Thereafter, the skin was sutured with a surgical thread and rats were allowed to recover before returning to their cages.

Sample collection. At the end of the experiment, rats were anesthetized with pentobarbital sodium $(75 \mathrm{mg} / \mathrm{kg}$, i.p. $)$, soleus and plantaris muscles were rapidly removed, and the rats were euthanized by cardiac puncture. Muscle samples were trimmed of excess connective tissue, weighed, and the entire fiber was horizontally halved. The upper half was immediately frozen in liquid nitrogen and stored at $-80^{\circ} \mathrm{C}$ for biochemical analysis. The lower half was mounted in Optimal Cutting Temperature Tissue Tek (Electron Microscopy Sciences, Hatfield, PA, USA) and immersed in isopentane (Sigma, St. Louis, MO, USA) pre-cooled by liquid nitrogen and stored at $-80^{\circ} \mathrm{C}$ for further analysis.

Western blot analysis. Approximately $50 \mathrm{mg}$ of muscle sample was homogenized using a glass homogenizer (Glas-Col; Terre Haute, IN, USA) with an ice-cold homogenizing buffer containing $50 \mathrm{mM}$ Tris$\mathrm{HCl}$ (pH 7.5), $5 \mathrm{mM}$ EDTA, $1 \mathrm{mM}$ phenylmethane sulfonyl fluoride, and a protease inhibitor cocktail (Sigma) at a mass-to-buffer ratio of $20: 1$. The homogenates were centrifuged at $1,500 \times g$ for $10 \mathrm{~min}$ $\left(4^{\circ} \mathrm{C}\right)$, and both supernatant (cytosolic fraction) and pellet (myofibrillar fraction) were collected. The cytosolic fractions were further centrifuged at $10,000 \times g$ for $10 \mathrm{~min}\left(4^{\circ} \mathrm{C}\right)$ and the supernatant was collected. To remove debris from the myofibrillar fraction, pellets were suspended in ice-cold homogenizing buffer plus $1 \%$ Triton $\mathrm{X}-100$ and centrifuged at $1,500 \times g$ for $10 \mathrm{~min}\left(4^{\circ} \mathrm{C}\right)$ three times. The final pellets were re-suspended with $8 \mathrm{M}$ urea in 50 $\mathrm{mM}$ Tris- $\mathrm{HCl}(\mathrm{pH}$ 7.5). The cytosolic and myofibrillar fractions were aliquoted to determine the protein concentration in triplicate using bicinchoninic acid (BCA) assay kit (Thermo Scientific, Rockford, IL, USA) with bovine serum albumin (Sigma) as a standard.

The accumulation of ubiquitin conjugates and muscle RINGfinger-1 (MURF1) protein expression were measured using myofibrillar and cytosolic protein fractions, respectively. Protein in 
sample buffer solution $(1 \mathrm{mg} / \mathrm{ml})$ was denatured by heating at $60^{\circ} \mathrm{C}$ for $10 \mathrm{~min}$ and was then loaded into SDS-polyacrylamide gel. The myofibrillar protein was separated on a $5 \%$ stacking gel at $60 \mathrm{~V}$ for $30 \mathrm{~min}$ and on an $8 \%$ polyacrylamide gel at $90 \mathrm{~V}$ for $360 \mathrm{~min}$ at room temperature (RT). However, the cytosolic protein fraction was electrophoresis at $60 \mathrm{~V}$ for $30 \mathrm{~min}$ on a $5 \%$ stacking gel and $110 \mathrm{~V}$ for 90 min on a $10 \%$ separating gel. Proteins were then transferred for $90 \mathrm{~min}$ at $100 \mathrm{~V}$ onto nitrocellulose blotting membrane (Pall Corporation ${ }^{\circledR}$ Life science, Port Washington, NY, USA). Non-specific binding was blocked with $5 \%$ non-fat milk in Tris-buffered saline (TBS) plus Tween-20 (20 mM Tris, pH 7.5, $150 \mathrm{mM} \mathrm{NaCl}$, and $0.1 \%$ Tween-20) for $90 \mathrm{~min}$ at room temperature. The membrane was incubated with primary antibodies in blocking buffer overnight at $4^{\circ} \mathrm{C}$. The following primary antibodies were used: 1:200 antiubiquitin (sc8017; Santa Cruz Biotechnology, Santa Cruz, CA, USA), and 1:1,000 anti-MURF1 (AF5366; R\&D System, Minneapolis, MN, USA). Following a series of extensive washes with TBS plus Tween20 buffer, the membrane was incubated for 90 min with 1:10,000 goat anti-mouse IgG peroxidase conjugated (31430; Thermo Scientific) or 1:1,000 rabbit anti-goat IgG conjugated horseradish peroxidase (HAF017; R\&D System) secondary antibodies. Protein bands were visualized by enhanced chemiluminescence (ECL) (Thermo Scientific) and exposed to CL-XPosure film (Thermo Scientific). Band intensity was measured using Image $\mathrm{J}$ software version $1.44 \mathrm{o}$ (NIH; National Institutes of Health, Bethesda, MD, USA).

Histological analysis. Embedded muscles were placed at $-20^{\circ} \mathrm{C}$ for $30 \mathrm{~min}$ before sectioning at $10 \mu \mathrm{m}$ thickness using a cryostat (Lelica, Wetzlar, Germany). Muscle sections were stained with hematoxylin and eosin (H\&E) and mounted with Permount (Fisher Scientific, Loughborough, Leicestershire, UK) to visualize muscle morphology and determine the fiber cross-sectional area (CSA). The image acquisitions were taken under a light microscope (Olympus Tokyo, Japan) with digital camera (Olympus) at $\times 200$ magnification. Four images per muscle section were captured to determine the CSA with cell Sens Dimension 1.8.1 software (Olympus). The muscle fiber CSA was quantified by using ImageJ software version $1.44 \mathrm{o}(\mathrm{NIH})$

Statistical analysis. Data are presented as means \pm SEM. Normal distribution and homogeneity of variance were determined using Shapiro-Wilk test and Levene's test, respectively. One-way ANOVA with Student-Newman-Keuls post hoc test was used to determine differences between treatment conditions. When homogeneity of variance was not assumed, data were analyzed by the KruskalWallis test. If statistical significance was detected, Dunn's test was used to indicate significant differences with the level of acceptance at $p<0.05$. Statistical analysis was performed using SPSS version 17.0 (Chicago, IL, USA).

\section{Results}

Effect of 20 E on body weight, muscle wet weight and myofibrillar protein content after tenotomy. Eight days after tenotomy, the body weight of TEN and TEN+20E groups were significantly $(p<0.05)$ lower than that of the CON group (Figure 1A). There were significant $(p<0.01)$ decreases in the absolute and relative wet weight of soleus muscles (by $58.97 \%$ and $54.4 \%$, respectively) 8 days after
Achilles tendon transection compared to the CON group. Additionally in the tenotomized groups, the absolute and relative plantaris wet weights decreased by $18.85 \%$ and $11.25 \%$, respectively, as compared with the CON group. Interestingly, 20E treatment attenuated tenotomy-induced muscle loss in soleus muscle, the reduction of muscle wet weight was less in the TEN+20E group when compared with the TEN group (49.13\% vs. 58.97\%) (Figure 1C and D). Corresponding with the muscle wet weight, the myofibrillar protein content was significantly reduced in both soleus and plantaris muscles ( $p<0.01$ and $p<0.05$, respectively) in TEN compared with CON groups. However, 20E treatment had no additional effect on tenotomized muscle.

Effect of 20E on muscle histology and fiber CSA after tenotomy. Muscle morphology was assessed by $\mathrm{H} \& \mathrm{E}$ staining. As seen in Figure 2A, the normal muscle fibers were polygonal shapes and packed together to form muscle bundles. In contrast, the muscle fibers revealed smaller in size associated with the significant $(p<0.01)$ reduction of mean fiber CSA in soleus and plantaris muscles of tenotomized groups when compared with the CON group. However, 20E treatment did not alleviate the tenotomyinduced reduction of fiber CSA (Figure 2). In parallel, muscle fiber distribution in TEN and TEN+20E groups presented a leftward shift of the CSA curve in both muscles examined (Figure 2B).

Effect of 20 E on components of the UPS after tenotomy. In order to determine whether tenotomy-induced muscle atrophy involved the activation of the UPS pathway, ubiquitin conjugates were examined in the myofibrillar fraction from both soleus and plantaris muscles. As expected, tenotomy significant $(p<0.01)$ increased high molecular weight (HMW.) ubiquitin conjugates in both soleus and plantaris muscles $(151.1 \%$ and $128.3 \%$, respectively) compared to the $\mathrm{CON}$ group. Interestingly, the level of HMW-ubiquitin conjugates was attenuated by $63.1 \%$ in soleus of tenotomized rat treated with $20 \mathrm{E}$, but this effect was not observed in the plantaris muscles (Figure $3 \mathrm{~A}$ and $\mathrm{B}$ ).

Since E3 ligases are considered to be rate-limiting in the UPS pathway and their mRNA levels were consistently upregulated in several models of muscle disuse atrophy, MURF1 protein expression was also determined in this study. Surprisingly, MURF1 protein expression in soleus and plantaris muscles was not significantly affected by tenotomy nor by $20 \mathrm{E}$ (Figure $4 \mathrm{~A}$ and $\mathrm{B}$ ).

\section{Discussion}

This study aimed to investigate the effect of $20 \mathrm{E}$ on skeletal muscle atrophy in both slow- and fast-twitch muscles following tenotomy. The results demonstrated that subcutaneous 
A

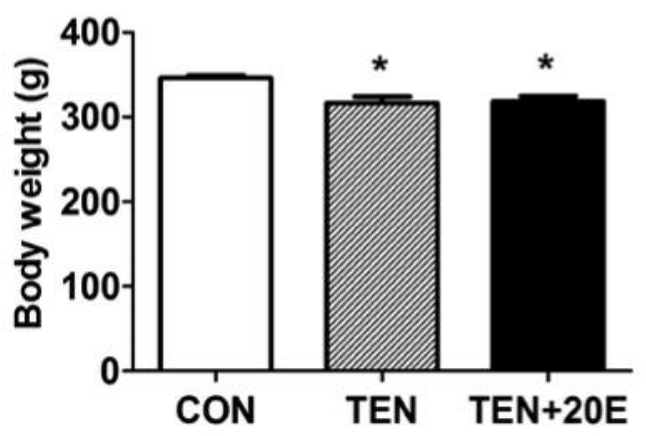

C

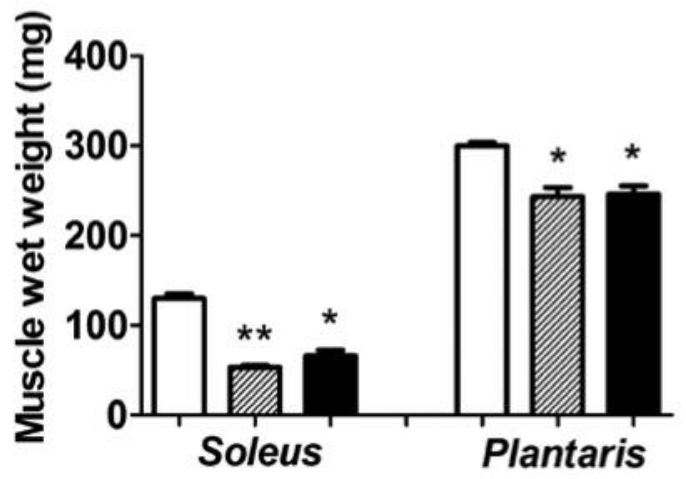

B

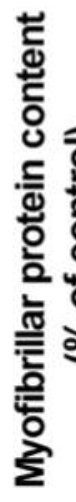

150

D

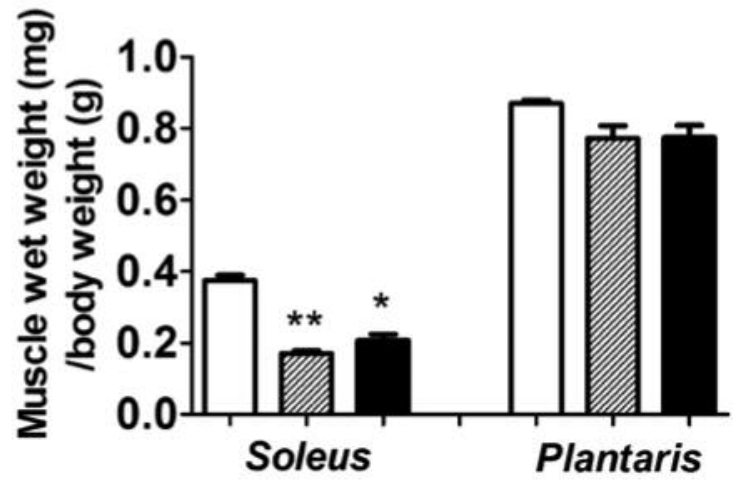

Figure 1. Effects of 20-hydroxyecdystone (20E) on body weight (A), myofibrillar protein content (B), absolute muscle wet weight (C) and relative muscle wet weight normalized to body weight $(D)$ of soleus and plantaris muscles 8 days after tenotomy ( $n=8$ rats $/ g$ roup). $* p<0.05$ and $* * p<0.01$, vs. control non-tenotomized (CON) rats for each muscle.

administration of $5 \mathrm{mg} / \mathrm{kg} \mathrm{BW}$ of $20 \mathrm{E}$ tended to alleviate tenotomy-induced reduction of muscle mass and attenuate tenotomy-induced ubiquitinated protein in soleus muscle. Despite this, 20E had no additional effect on body weight, myofibrillar protein content, or fiber CSA in either muscle after tenotomy.

Our findings that transection of the Achilles tendon for 8 days induced muscle atrophy in both soleus and plantaris muscles and this atrophic effect was greater in the predominantly slow soleus muscle than the predominantly fast plantaris muscle were in accordance with other literature (20). In the present study, the finding that $20 \mathrm{E}$ treatment had a tendency to preserve muscle mass in slow-twitch muscles but had no effect on fast-twitch muscles following tenotomy was in line with previous reports on the effect of anabolic steroid supplements $(24,25)$. In one study, $2 \mathrm{mg} / \mathrm{kg} \mathrm{BW}$ of nandrolone decanoate injection for 1 week increased muscle mass and myosin heavy chain type I expression on rat regenerating soleus but not on predominantly fast extensor digitorum longus muscles (24). Moreover, 1-week administration of $100 \mathrm{mg}$ testosterone enanthate increased muscle fiber diameter 1.5-fold more in slow fiber compared to fast fiber vastus lateralis muscle in elderly men (25).

In this study, the dose of $5 \mathrm{mg} / \mathrm{kg} \mathrm{BW}$ of $20 \mathrm{E}$ was applied to the rat, since the dose-dependent effect of this compound on the muscle fiber growth has been shown and this was an effective dose to promote regeneration in rat skeletal muscle (15). There is also evidence that intraperitoneal injection of $5 \mathrm{mg} / \mathrm{kg} \mathrm{BW}$ of $20 \mathrm{E}$ for 7 days enhanced protein synthesis in mouse heart and muscle (26), increased body and muscle weight, as well as liver growth in castrated or ovariectomized rats, but had no any androgenic effect (14). Furthermore, continuous infusion of $20 \mathrm{E}(5 \mathrm{mg} / \mathrm{kg} \mathrm{BW})$ for 5 days using subcutaneously implanted osmotic pump revealed an increase in mass of triceps brachii muscle, but there were no differences in the masses of tibialis anterior, biceps femoris, and gastrocnemius muscles, nor any body weight change in mice (27). 
A
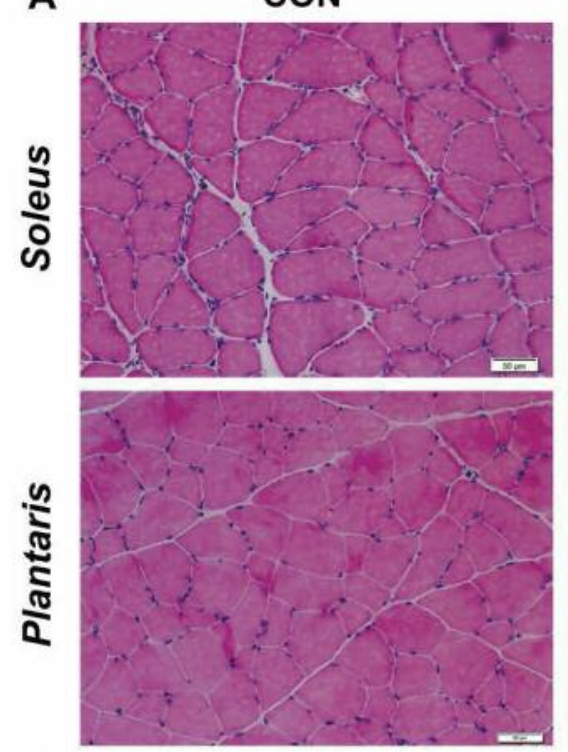

B

Soleus

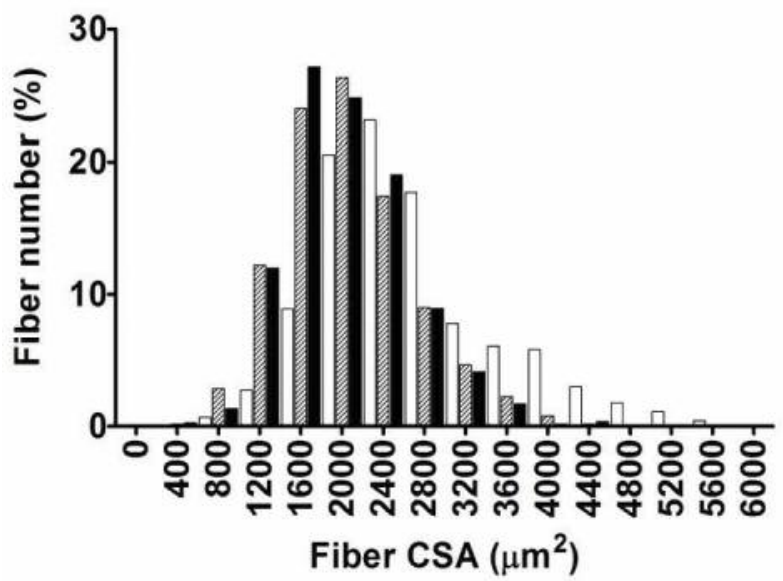

C

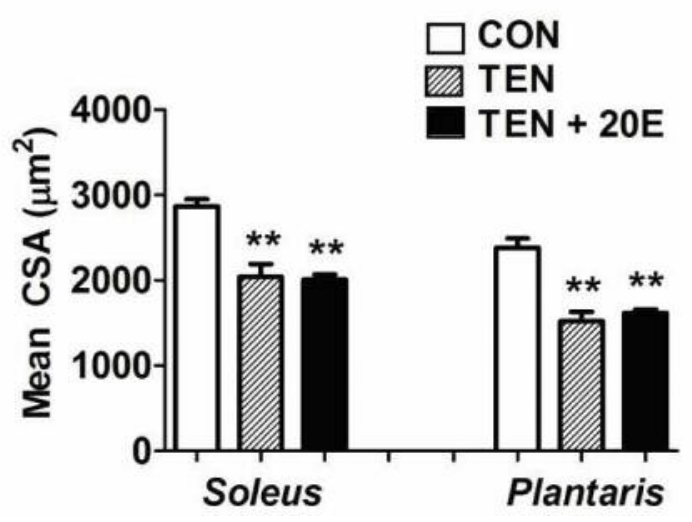

Figure 2. Effects of 20-hydroxyecdystone (20E) on muscle morphology and fiber cross-sectional area (CSA) in soleus and plantaris muscles 8 days after tenotomy. A: Hematoxylin and eosin staining of soleus and plantaris muscle cross-sections. Left panel is muscle from control non-tenotomized rats (CON); middle panel is muscle from tenotomized rat (TEN); right panel is muscle from tenotomized rat treated with 20E (TEN+20E). Scale bars $=50 \mu \mathrm{m}$. B: Histogram of fiber CSA distribution (a total of 1168 fibers from CON, 1113 fibers from TEN, and 1109 fibers from TEN+20E of soleus muscle; 1192 fibers from CON, 1225 fibers from TEN, and 1172 fibers from TEN $+20 E$ of plantaris muscle) C: Mean fiber CSA ( $n=3$ rats/group). $* * p<0.01$ vs. CON for each muscle. 
A

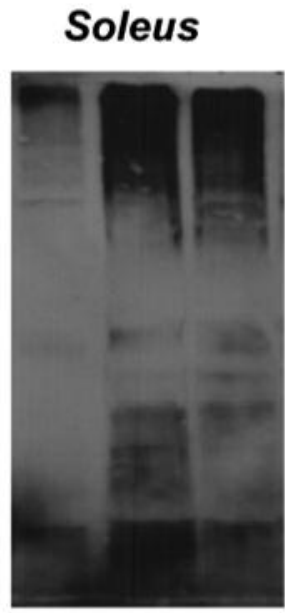

CON TEN TEN+20E
Plantaris

$<210 \mathrm{kDa}>$

$<160 \mathrm{kDa}>$

$<110 \mathrm{kDa}>$

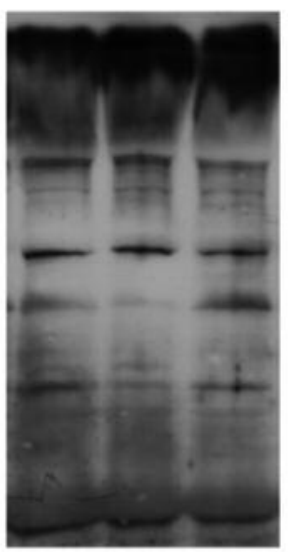

CON TEN TEN+20E

B
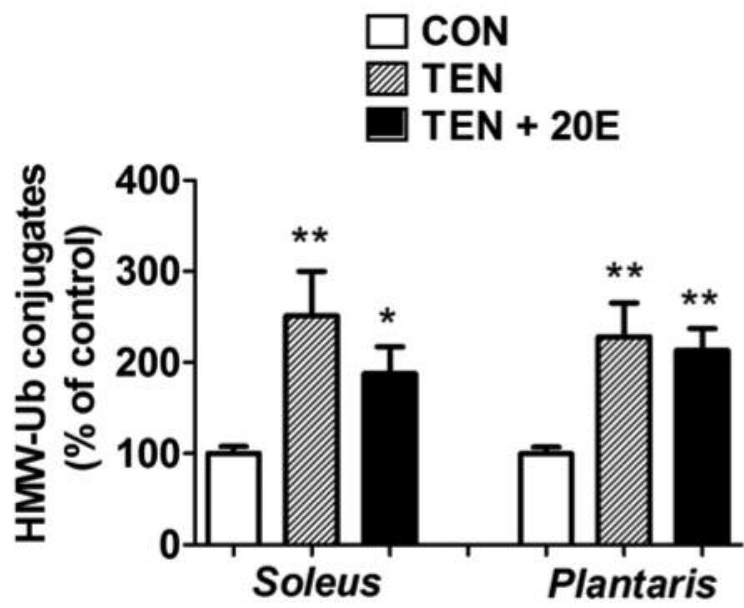

Figure 3. Effects of 20-hydroxyecdystone (2OE) on high molecular weight (HMW)-ubiquitin (Ub) conjugates in soleus and plantaris muscles 8 days after tenotomy. A: Western blot analysis of HMW-Ub conjugates. B: Quantified data of HMW-Ub (n=6-7 rats/group). *p<0.05 and **p<0.01, vs. control non-tenotomized (CON) rats for each muscle.

Although the anabolic effect of $20 \mathrm{E}$ was demonstrated in several studies, its effect on body weight or muscle mass was inconsistent $(15,27)$. These variations may stem from the distinction in animal strains and the animal models used in those studies, and also the differences in routes and methods of $20 \mathrm{E}$ administration. $20 \mathrm{E}$ was found to be rapidly eliminated by various routes $e . g$. bile, urinary and feces with low toxicity in mammals (12). Thus, the half-life of this compound in rodents is short e.g. $8 \mathrm{~min} 15 \mathrm{sec}$ in mice (11). This may explain discrepancies in muscle mass adaptation to $20 \mathrm{E}$ treatment. Considering the effect of $20 \mathrm{E}$ on disuse muscle atrophy, further study is required to investigate the optimal dose and duration of $20 \mathrm{E}$ administration, and to determine the plasma concentration of $20 \mathrm{E}$ throughout the experiment.
In this study, 20E treatment had no effect on fiber CSA in tenotomy-induced muscle atrophy. This finding was in contrast with that of Toth et al., who reported that $20 \mathrm{E}$ increased soleus CSA following cardiotoxin-induced muscle injury (15). The distinction may result from the differences in animal models used in the study.

There are three major conditions regulating muscle fiber size: i) the number of myonuclei, ii) the rate of protein synthesis, iii) the rate of protein degradation. A previous study proposed that $20 \mathrm{E}$ exerted an anabolic effect (increased fiber CSA) in regenerating soleus muscle via an increased myonuclear number (15). In response to stimuli such as muscle injury, the resident mesenchymal stem cells, termed satellite cells, become activated, proliferate and express myogenic markers (myoblasts), leading them to fuse together 
A

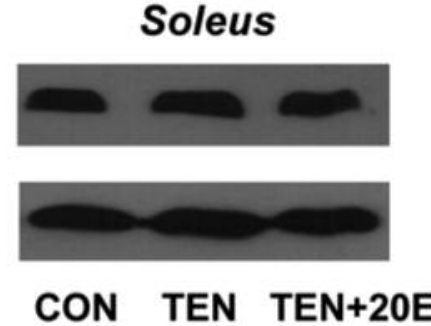

\section{$<$ MURF1 > $(41 \mathrm{kDa})$} $<\alpha$-Tubulin > $(55 \mathrm{kDa})$

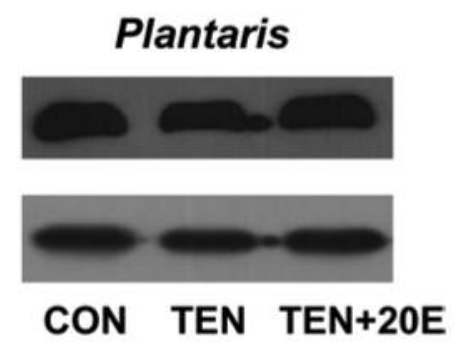

B

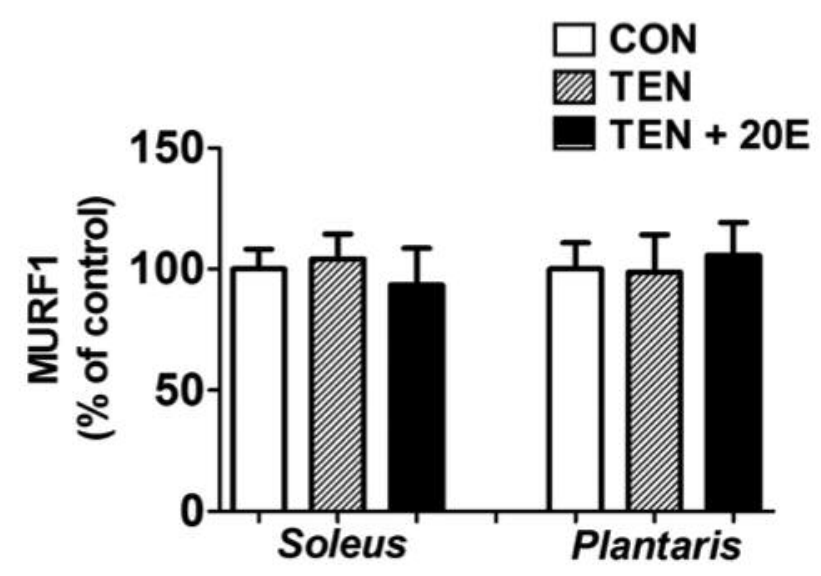

Figure 4. Effects of 20-hydroxyecdystone (20E) on muscle RING-finger-1 (MURF1) protein expression in soleus and plantaris muscles 8 days after tenotomy. A: Western blot analysis of MURF1 protein expression. B: Quantified data of MURF1 expression. MURF1 band density was normalized using $\alpha$-tubulin ( $n=5$ rats/group).

to form new multinucleated muscle fibers or to repair existing myofibers (28). Nevertheless, many studies demonstrated that myonuclei number did not change during disuse muscle atrophy $(29,30)$. It is possible that $20 \mathrm{E}$ administration had no additional effect on myogenic precursor cell activation in tenotomized muscle. Thus, $5 \mathrm{mg} / \mathrm{kg} \mathrm{BW}$ of $20 \mathrm{E}$ treatment may be an effective dose in regenerating soleus fiber CSA but is not sufficient for increasing the CSA in atrophied muscle.

Muscle atrophy occurs when the balance between protein synthesis and protein degradation is in favor of degradation, leading to the loss of myofibrillar protein (31). In this study, tenotomy induced the loss of myofibrillar protein associated with the reduction of fiber CSA in both soleus and plantaris muscles. Although the precise mechanism leading to skeletal muscle atrophy is not clearly understood, the UPS, which is the major proteolytic system, has been implicated in the pathogenesis of skeletal muscle wasting, including muscle disuse atrophy and cachexia (32). Our finding that tenotomy increased accumulation of ubiquitinated proteins in both muscles is consistent with another study (5). Interestingly, $20 \mathrm{E}$ treatment resulted in lower ubiquitinated protein accumulation only in soleus muscle, not plantaris muscle. Collectively, these data indicate that $20 \mathrm{E}$ can alleviate tenotomy-induced atrophy, particularly in slow muscle, at least in part through a muscle-specific inhibition of the ubiquitin-proteasome pathway.

Nevertheless, the finding that tenotomy did not alter protein expression of MURF1, muscle-specific E3 ligase, in both muscles examined was unexpected, given that this protein is mostly up-regulated in various models of muscle atrophy including immobilization, denervation, and hindlimb suspension (33). The reason behind this discrepancy may stem from the use of different animal models of muscle atrophy. Microarray analysis of tenotomized muscle in mice demonstrated increased expression of genes involved in lysosomal protein degradation (e.g. cathepsin) (1) and calcium-activated protease (34) in mouse tenotomized muscle. Furthermore, a recent study demonstrated that the MURF 1 mRNA tended to increase to the highest level at after 3 days and then declined at 7 days in the ambulatory muscles following immobilization (35). Thus, in this study, it is possible that the level of MURF1 protein expression might have already returned to the baseline level at 8 days after tenotomy. Therefore, other proteolytic mechanisms and time course need to be further investigated to verify the effect of $20 \mathrm{E}$ on tenotomy-induced muscle atrophy. 
In conclusion, we demonstrated that $20 \mathrm{E}$ attenuated tenotomy-induced muscle atrophy in predominantly slowtwitch muscle, partially mediated by ubiquitin proteasome pathway in rat skeletal muscle. Thus, $20 \mathrm{E}$ may be beneficial as a supplement for promoting muscle recovery from disuse muscle atrophy.

\section{Conflicts of Interest}

The Authors declare that there are no conflicts of interest in regard to this study.

\section{Acknowledgements}

This work was supported by grants from Mahidol University under the National Research Universities. Partial support from The Thailand Research Fund (DBG5980003) is gratefully acknowledged. We also thank the Olympus Bioimaging Center, Faculty of Science, Mahidol University for technical support.

\section{References}

1 Bialek P, Morris C, Parkington J, St Andre M, Owens J, Yaworsky P, Seeherman H and Jelinsky SA: Distinct protein degradation profiles are induced by different disuse models of skeletal muscle atrophy. Physiol Genomics 43: 1075-1086, 2011.

2 Cruz-Jentoft AJ, Baeyens JP, Bauer JM, Boirie Y, Cederholm T, Landi F, Martin FC, Michel JP, Rolland Y, Schneider SM, Topinková E, Vandewoude M and Zmaboni M: Sarcopenia: European consensus on definition and diagnosis: Report of the European Working Group on Sarcopenia in Older People. Age Ageing 39: 412-423, 2010.

3 Sandri M: Signaling in muscle atrophy and hypertrophy. Physiology 23: 160-170, 2008.

4 Krawiec BJ, Frost RA, Vary TC, Jefferson LS and Lang CH: Hindlimb casting decreases muscle mass in part by proteasomedependent proteolysis but independent of protein synthesis. Am J Physiol Endocrinol Metab 289: 969-980, 2005.

5 Yimlamai T, Dodd SL, Borst SE and Park S: Clenbuterol induces muscle-specific attenuation of atrophy through effects on the ubiquitin-proteasome pathway. J Appl Physiol 99: 71-80, 2005.

6 Gorelick-Feldman J, Maclean D, Ilic N, Poulev A, Lila MA, Cheng D and Raskin I: Phytoecdysteroids increase protein synthesis in skeletal muscle cells. Agric Food Chem 56: 35323537, 2008.

7 Sláma K and Lafont R: Insect hormones-ecdysteroids: their presence and actions in vertebrates. Eur J Entomol 92: 355-355, 1995.

8 Dinan L: Phytoecdysteroids: biological aspects. Phytochemistry 57: 325-339, 2001.

9 Ogawa S, Nishimoto $\mathrm{N}$ and Matsuda H: Pharmacology of ecdysones in vertebrates. In: Invertebrate Endocrinology and Hormonal Heterophylly. Burdette WJ (ed.). Berlin, Springer., pp. 341-344, 1974.

10 Simon $\mathrm{P}$ and Koolman J: Ecdysteroids in vertebrates: pharmacological aspects. In: Ecdysone from Chemistry to Mode of Action. Koolman J (ed.). Stuttgart, Georg Thieme Verlag., pp. 254-259, 1989.
11 Dzhukharova MK, Sakhibov A, Kasymov B, Syrov V, Takanaev $A$ and Saatov Z: Pharmacokinetics of ecdysterone in experiments. Pharm Chem J 21: 689-692, 1987.

12 Lafont $\mathrm{R}$ and Dinan L: Practical uses for ecdysteroids in mammals including humans: an update. J Insect Sci 3: 7, 2003.

13 Bathori M, Toth N, Hunyadi A, Marki A and Zador E: Phytoecdysteroids and anabolic-androgenic steroids-structure and effects on humans. Curr Med Chem 15: 75-91, 2008.

14 Syrov VN: Mechanism of the anabolic action of phytoecdisteroids in mammals. In: Nauchnye Doki Vyss Shkoly Biol Nauki. Moscow, Moskva., pp. 16-20, 1984.

15 Toth N, Szabo A, Kacsala P, Heger J and Zador E: 20Hydroxyecdysone increases fiber size in a muscle-specific fashion in rat. Phytomedicine 15: 691-698, 2008.

16 Chermnykh NS, Shimanovskii NL, Shutko GV and Syrov VN: The action of methandrostenolone and ecdysterone on the physical endurance of animals and on protein metabolism in the skeletal muscles. Farmakol Toksikol 51: 57-60, 1988.

17 Gorelick-Feldman J, Cohick W and Raskin I: Ecdysteroids elicit a rapid $\mathrm{Ca}^{2+}$ flux leading to AKT activation and increased protein synthesis in skeletal muscle cells. Steroids 75: 632-637, 2010.

18 Jamali AA, Afshar P, Abrams RA and Lieber RL: Skeletal muscle response to tenotomy. Muscle Nerve 23: 851-862, 2000.

19 Wang Y and Pessin JE: Mechanisms for fiber-type specificity of skeletal muscle atrophy. Curr Opin Clin Nutr Metab Care 16: 243-250, 2013.

20 Hirunsai M, Srikuea R and Yimlamai T: Heat stress promotes extracellular matrix remodelling via TGF-betal and MMP2/TIMP-2 modulation in tenotomised soleus and plantaris muscles. Int J Hyperthermia 31: 336-348, 2015.

21 Werawattanametin K, Podimuang V and Suksamrarn A: Ecdysteroids from Vitex glabrata. J Nad Prod 49: 365-366, 1986.

22 Kumpun S, Girault JP, Dinan L, Blais C, Maria A, DauphinVillemant C, Yingyongnarongkul B, Suksamrarn A and Lafont $\mathrm{R}$ : The metabolism of 20-hydroxyecdysone in mice: relevance to pharmacological effects and gene switch applications of ecdysteroids. J Steroid Biochem Mol Biol 126: 1-9, 2011.

23 Lafont R, Harmatha J, Marion-Poll F, Dinan L and Wilson I. Ecdybase. In: The Ecdysone Handbook. Praha Czech Republic, Cybersales, 2002.

24 Ferry A, Noirez P, Page CL, Salah IB, Daegelen D and Rieu M: Effects of anabolic/androgenic steroids on regenerating skeletal muscles in the rat. Acta Physiol Scand 166: 105-110, 1999.

25 Fitts RH, Peters JR, Dillon EL, Durham WJ, Sheffield-Moore M and Urban RJ: Weekly versus monthly testosterone administration on fast and slow skeletal muscle fibers in older adult males. J Clin Endocrinol Metab 100: E223-231, 2015.

26 Khimiko I, YuI M, Efremova O and Sidorenko L: The influence of ecdysterone on the biosynthesis of proteins and nucleic acids in mouse organs. Khimiko-Farmatsevticheskii Zhurnal 34: 3-5, 2000.

27 Cheng DM, Kutzler LW, Boler DD, Drnevich J, Killefer J and Lila MA: Continuous infusion of 20-hydroxyecdysone increased mass of triceps brachii in C57BL/6 mice. Phytother Res: PTR 27: 107-111, 2013.

28 Hawke TJ and Garry DJ: Myogenic satellite cells: physiology to molecular biology. J Appl Physiol 91: 534-551, 2001.

29 Kasper CE and Xun L: Cytoplasm-to-myonucleus ratios in plantaris and soleus muscle fibres following hindlimb suspension. J Muscle Res Cell Motil 17: 603-610, 1996. 
30 Bruusgaard JC, Egner IM, Larsen TK, Dupre-Aucouturier S, Desplanches D and Gundersen K: No change in myonuclear number during muscle unloading and reloading. J Appl Physiol 113: 290-296, 2012.

31 Costamagna D, Costelli P, Sampaolesi M and Penna F: Role of Inflammation in Muscle Homeostasis and Myogenesis. Mediators Inflamm 2015: 805172, 2015.

32 Schiaffino S, Dyar KA, Ciciliot S, Blaauw Ba and Sandri M: Mechanisms regulating skeletal muscle growth and atrophy. FEBS J 280: 4294-4314, 2013.

33 Bodine SC, Latres E, Baumhueter S, Lai VK, Nunez L, Clarke BA, Poueymirou WT, Panaro FJ, Na E, Dharmarajan K, Pan ZQ, Valenzuela DM, DeChiara TM, Stitt TN, Yancopoulos GD and Glass DJ: Identification of ubiquitin ligases required for skeletal muscle atrophy. Science 294: 1704-1708, 2001.
34 Baker JH and Margolis RN: Calcium-activated protease activity in tenotomized muscle. Muscle \& nerve 10: 34-40, 1987.

35 Okamoto T, Torii S and Machida S: Differential gene expression of muscle-specific ubiquitin ligase MAFbx/Atrogin-1 and MURF1 in response to immobilization-induced atrophy of slowtwitch and fast-twitch muscles. J Physiol Sci 61: 537-546, 2011.

Received September 22, 2016

Revised October 1, 2016

Accepted October 6, 2016 